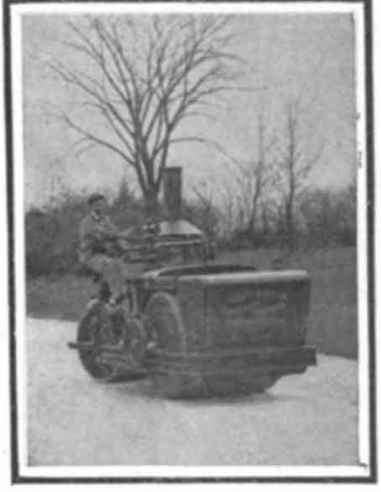

\section{THE MOTOR CAR AND THE ROAD}

\section{THE DESTRUCTIVE EFFECT OF HIGH SPEED.}

\author{
BY LOGAN WALLER PAGE,
}

DIRECTOR OF THE OFFICE OF PUBLIC ROADS, UNITED STATES DEPARTMENT OF AGRICULTURE.

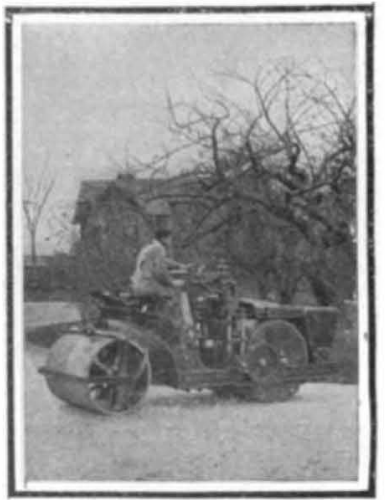

The most serious and difficult problem now engaging the attention of highway engineers all over the world is the preservation of the crushed stone road under the destructive action of motor vehicles, and the devising of new methods of construction adapted to the requirements of this twentieth century traffic. That the automobile has come to stay no one will dispute. It is estimated that there are already about $250,000 \mathrm{ma}$ chines owned in the United States, and the number is and the iron-tired wheels passing over the road from time to time were depended upon to wear off a suffcient amount of rock dust to replace that carried away by wind and water and this, under the action of moisand the bond of the road surface. When the road was subjected to drought, the conditions were made normal by regular sprinkling. With the advent of the automobile, a totally new condition prevails. The rubber- the effect were produced by suction or vacuum, the action of both front and rear wheels should be some what similar at least. It seems apparent to the writer, therefore, that the road best adapted to motor traffic is the road which will best resist this powerful tractive shear. It has already been demonstrated that no plain macadam road is capable of resisting this force.

While the destruction of the road may be considered as the most tangible and serious problem, the dust

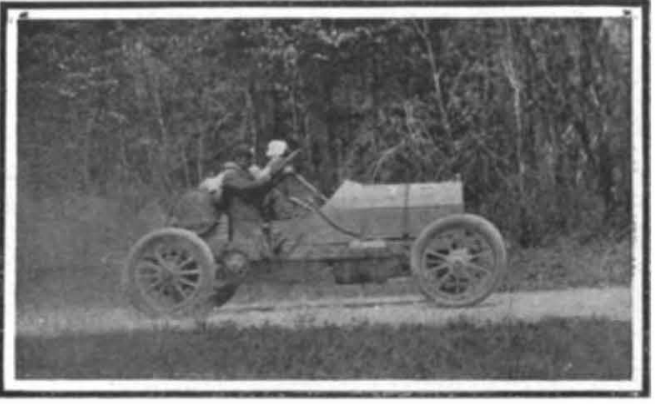

Twenty miles an honr.

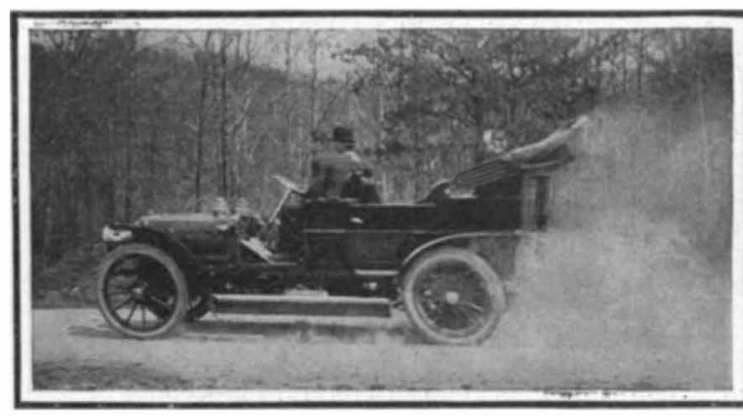

Thirty miles an hour.

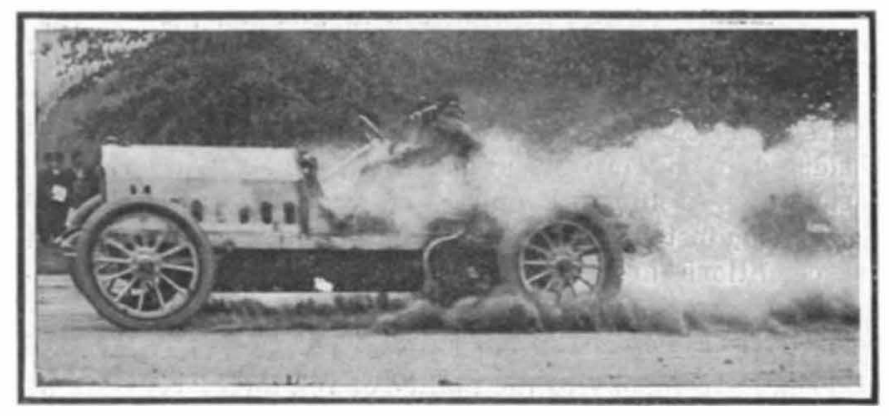

Eighty miles an hour.

THE DISINTEGRATING EFFECT OF AN AUTOMOBILE TRAVELING ON AN ORDINARY MACADAK ROAD AT DIFFERENT SPEEDS.

increasing at a marvelous rate. In France, which is credited with having the most superb system of roads in the world, built at a cost of about $\$ 625,000,000$, a great InternationaI Road Congress was sanctioned by the. French government and held at Paris in October, 1908. So alarming were the ravages caused by motor traffic on the costly. French road system that the purpose of the meeting was announced to be "The Adaptation of Roads to Modern Methods of Locomotion." In the United States, the problem as yet is a vital one only near the great centers of population, for the reason that but a small percentage of the total mileage of roads is improved, and the motor traffic is largely confined to small areas of country, but it will of necessity become increasingly. important with the constantly in creasing use of the automobile.

The fact that must give us concern is that the old methods of construction which have stood every test for more than a hundred years are inadequate to meet the conditions of this new form of traffic, and that we are in the midst of a transition period which may eventually revolutionize the science and art of the road builder. The highway engineer of to-day is called upon to ascertain in what way the automobile injures the road, what is the exact cause of the injury, and finally to devise an adequate remedy.

When Trèsaguet, the great French engineer, made his report to the Council of Bridges and Roads in 1775, he set forth the principles of construction which, as modified and added to by John L. MacAdam in the early part of the nineteenth century, have proven adequate until the twentieth century. These great road builders and their successors sought to secure a road capable of withstanding the wear of iron-tired horse-drawn vehicles, for the motor-driven vehicle had no place in their philosophy. They worked upon the theory that the dust abraded from the crushed stone would fill the voids between the angular fragments and when wet would serve as a cement, thereby making the road surface practically a monolith. The iron-shod horses tired wheels moving at excessive speed fail to produce any new dust from the rock, but the tremendous shearing effect of the driving wheels forces the loose dust on the road into the air in great clouds, and, as the body of the machine displaces a large volume of air, the deflected currents carry the rock dust off the road, thereby effecting a permanent loss of the allessential binder. It follows that the road is soon stripped of its fine binding material, and the upper or wearing course of the stone is exposed. These stones, robbed of the binding material, are soon loosened by the badly raveled or disintegrated. It is, of course, apparent that the effects described are greatly intensified on curves where skidding is most frequent.

Highway and mechanical engineers have given much study to the action of the automobile on the road surface, and many ingenious theories have been advanced. While it is true that the slipping of the tire, the skidding, the shape of the car body, and the suction of the pneumatic tires all contribute to produce the effect, the most conclusive experiments seem to warrant the assertion that the great tractive force or shear exerted by the driving wheels of motor cars is the main factor. of injury. A series of tests conducted by the United States Office of Public Roads in 1908 produced some interesting results along this line. Cars of various weights and types were run over a measured course at different rates of speed and right-angle photographs taken of each run. A 60-horse-power car stripped for racing, weighing with driver and mechanician about 2,800 pounds, was driven over a stretch of road first at five miles an hour, each run being increased at the rate of five miles an nour until a speed of 60 miles was attained. Up to 20 miles an hour little or no effect was produced on the road, but from 20 miles an hour the effect was striking with each increase in speed. Little or no effect is produced by the front wheels. Practically the entire disturbance of the road is produced by the rear or driving wheels. If nuisance as intensified by motor traffic is most far reaching in its indirect effects. It has been claimed that nine-tenths of the dust produced by man comes from streets and highways, and someone has very aptly termed the public road the "national dust factory." The effect of the huge clouds of dust upon health must be very great, as most forms of disease are transmitted by this germ-laden dust. The damage to crops growing adjacent to the public highway through the dust nuisance is real and tangible, and particularly is this true of small fruits So extreme pas this condition become in certain districts certain districts that n effect upon some classes of live stock is most severe, cattle and horses in particular being susceptible to the germs of tuberculosis carried by the dust. The automobile cannot be held responsible for these forms of damage, but it has undoubtedly intensified them. The road builder is, therefore, called upon in many cases to mitigate the dust nuisance by devising a form of treatment which might be considered a palliative.

The efforts of progressive highway engineers are directed, therefore, primarily toward the preservation of our stone-surfaced roads and the construction of dustless roads, and secondly to minimizing or mitigatin the dust nuisance. The results so far accomplished tle attention has been given to the actual composition and characteristics of the materials employed.

It is evident from even the slightest consideration of the subject that the solution of the problem must come, for the most part, from the highway enginee rather than the automobile manufacturer and the legislator. Manufacturers have, to some extent, tried to reduce the dust-raising tendency of their machines by various mechanical devices. Experiments in England brought out the fact that cars fitted with bodies having either very great or very slight clearance raised less dust than those with an average clearance. Some novel devices were tried with more or less success, the

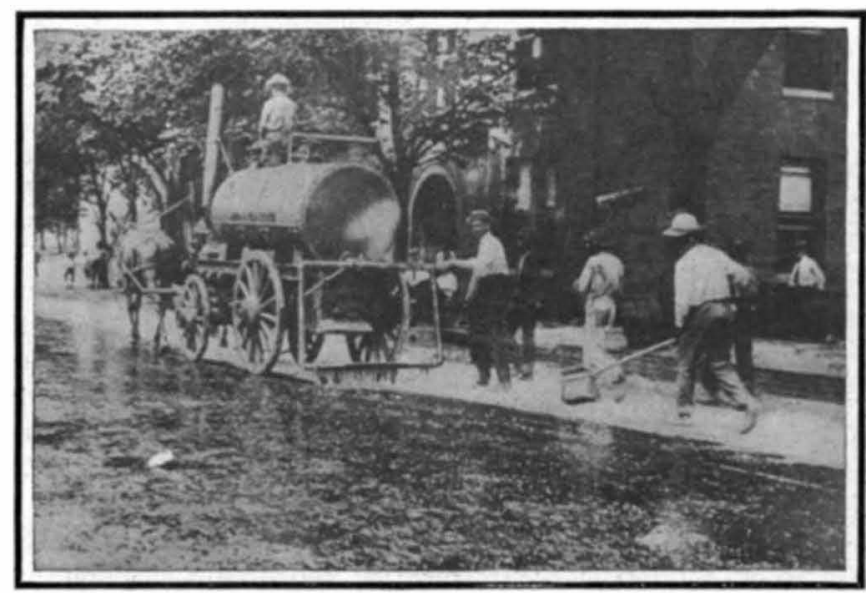

SPRINKIIYG TAR ON A ROAD AT JACKSON, TENN.

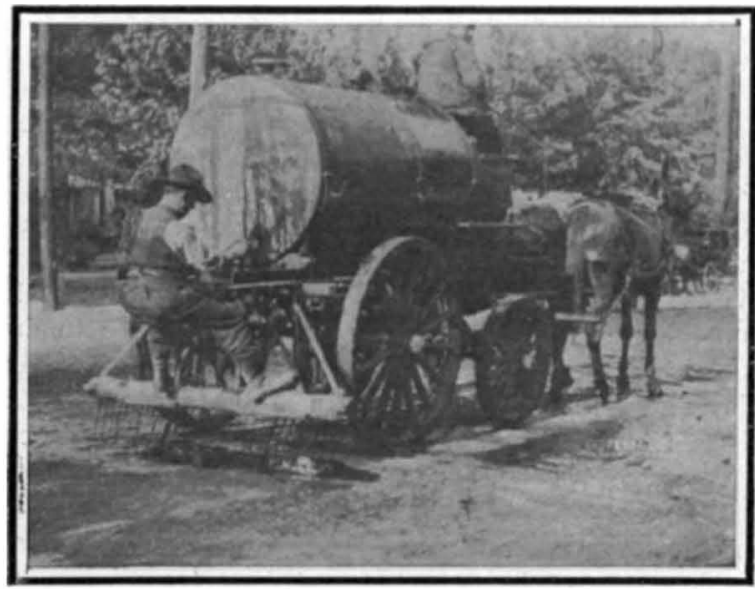

WAGON FOB FORCING BINDER INTO A ROAD.

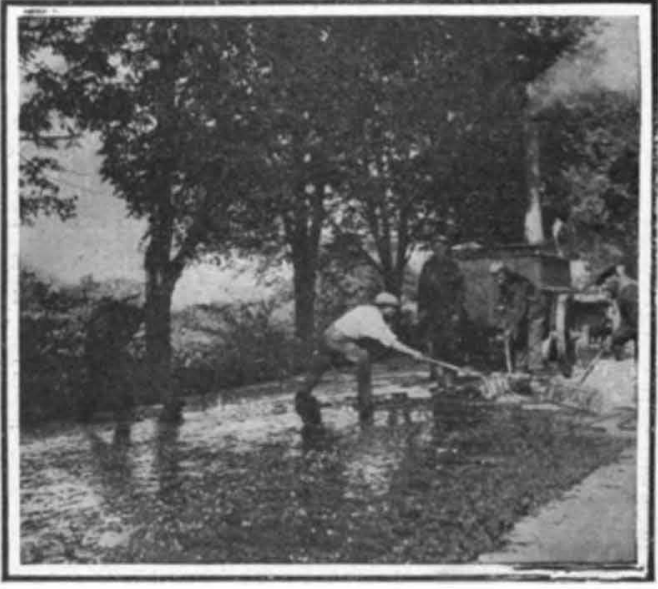

SPREADING TAR WITH BROOYE. 
Scientific American

best results being obtained from a car with a flat steel bottom overlapping the sides of the car, and shoes instead of mud guards. The under screen was six inches from the ground and projected beyond the radiator in front to catch deflected wind from the faces of the car and pass it between the screen and the car, instead of between the car and the road. It is an evident fact that the greater the speed the greater the amount of dust, and the greater the damage to the road. Steps have already been taken to combat the speed mania by the enactment of the most stringent speed regulations. Much difficulty is found, however, in enforcing these regulations.

The experiments conducted by highway engineers, particularly in France, England, and the United States, have been directed toward providing a stone-surfaced road with

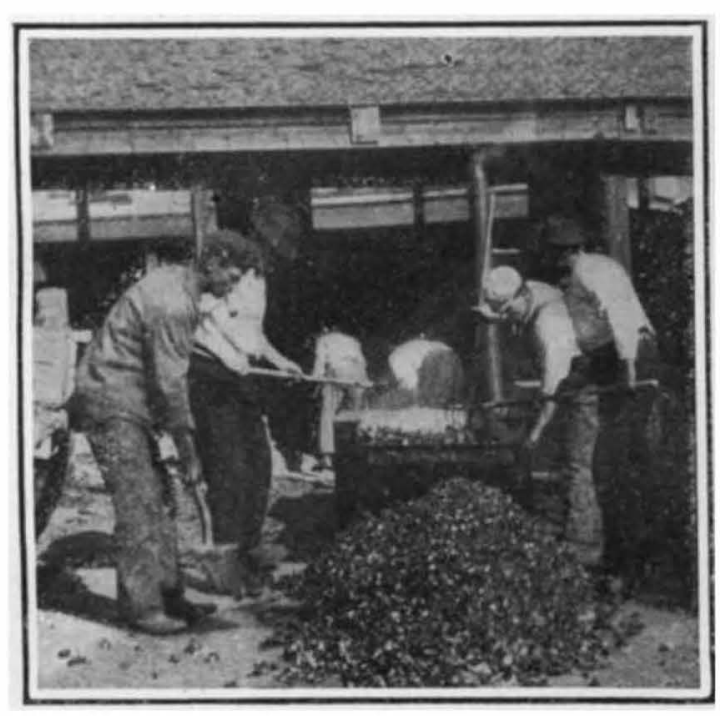

MIXING A BATCH OF MATERIAL OFF THE ROAD BY HAND MACHINE.

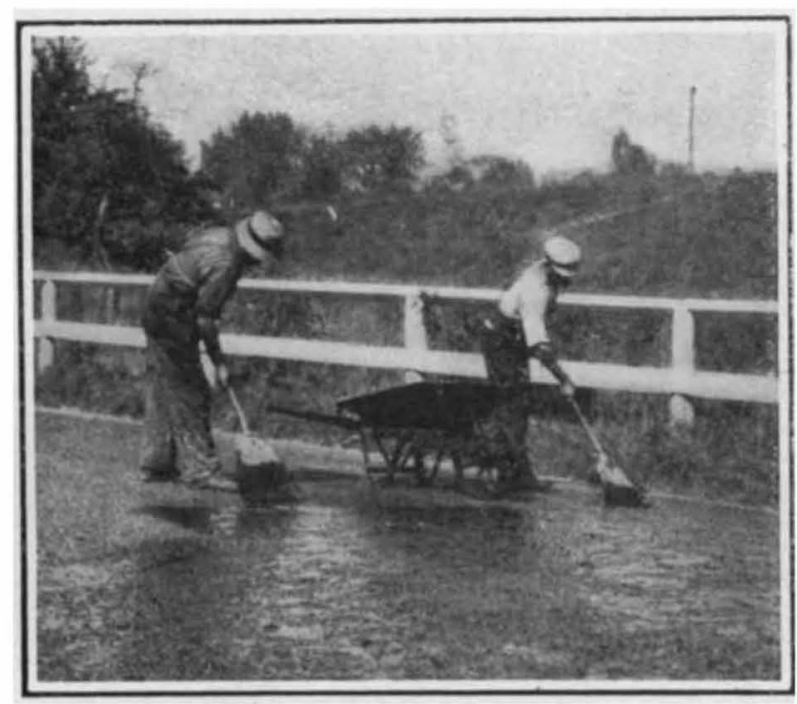

BITUMINOUS BINDER APPLIED WITH BROOMS FROM STEEL WHEELBARROWS.

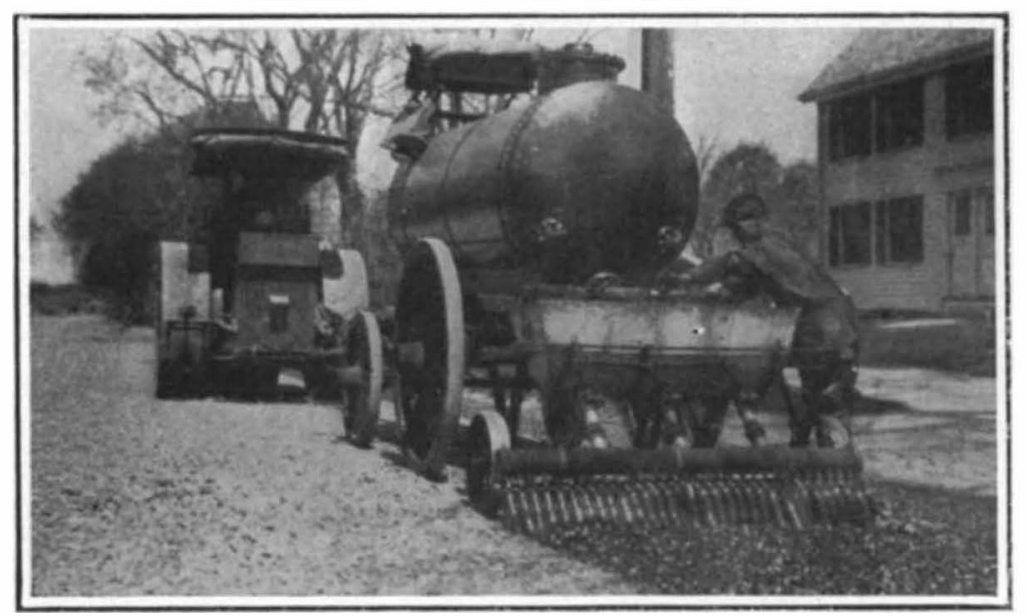

CONSTRUCTION OF BITUMINOUS MACADAM ROAD. BY PENETRATION OR GRODTING METHOD. HEAVY TAR IS APPLIED ON THE TOP COURSE OF STONE. binder more powerful than the rock dust For the purpose of presenting intelligently the experiments thus far conducted with special binders, the term "dust preventives" has been applied to all of the various binders having for their object either the suppression or the prevention of dust. These may be divided into two classes, temporary and permanent. The temporary binders serve merely as palliatives and require frequent renewal; the permanent binders, so called, enter into the structure of the road as a constituent element, and are either incorporated with the other materials at the time of the construction or applied later by a surface treatment.

In the class of temporary binders may be included water, salt solutions, light oils and tars, and oil and tar emulsions, while the (Continued on page 6.5 .)

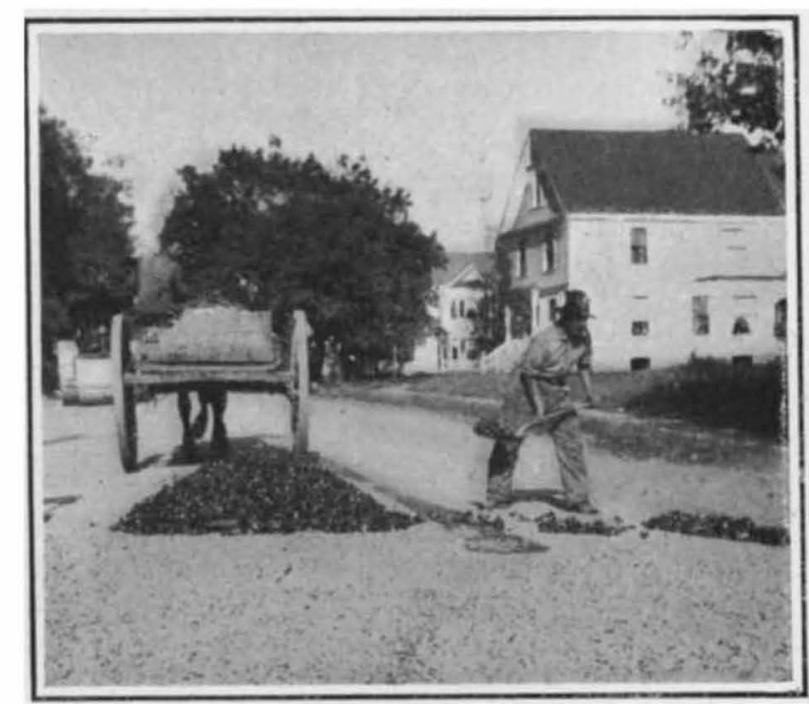

TARRED STONE DELIVERED ON THE ROAD ON PREVIOUSLY COATED WORK.

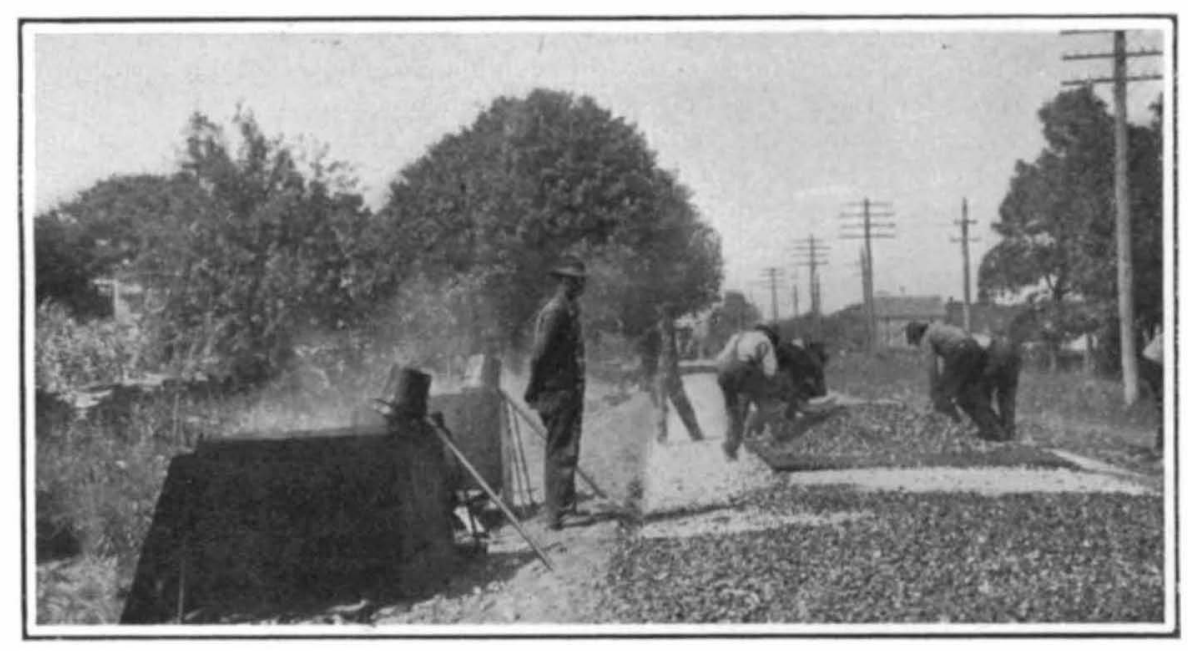

HAND MIXIXG OF BITUMINOUS BINDER ON THE ROAD.

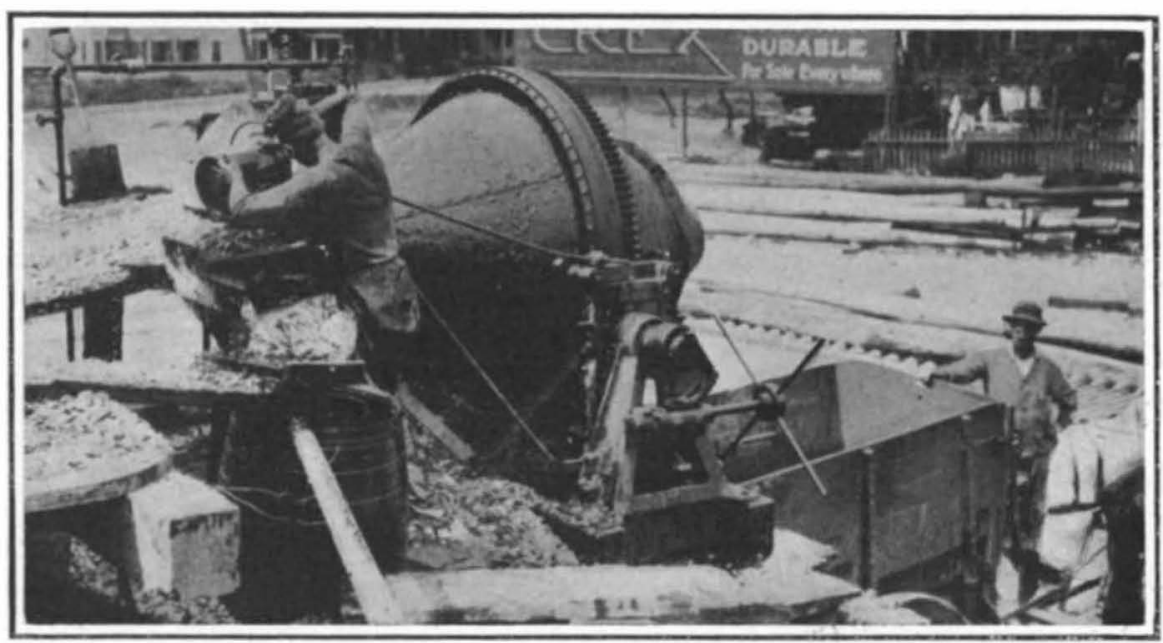

SMITH CONCRETE MIXER USED FOR MIXING ROAD-MAKING MATERIAL.

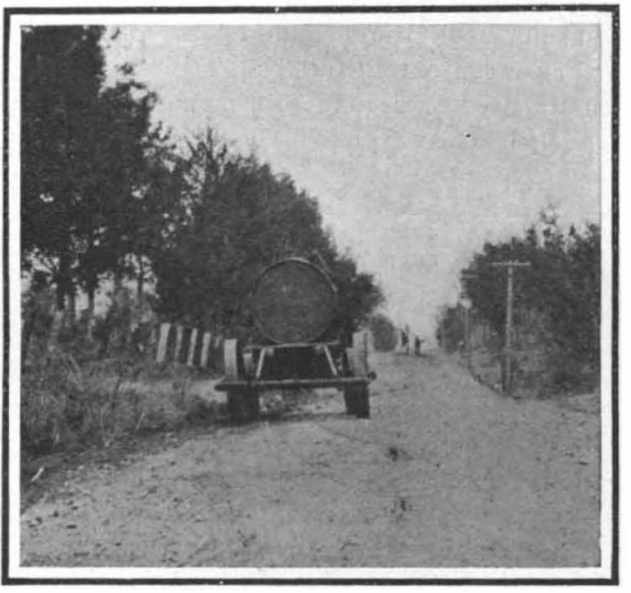

AN OBJECT LESSON ROAD AT ONIONTOWN, ALA.

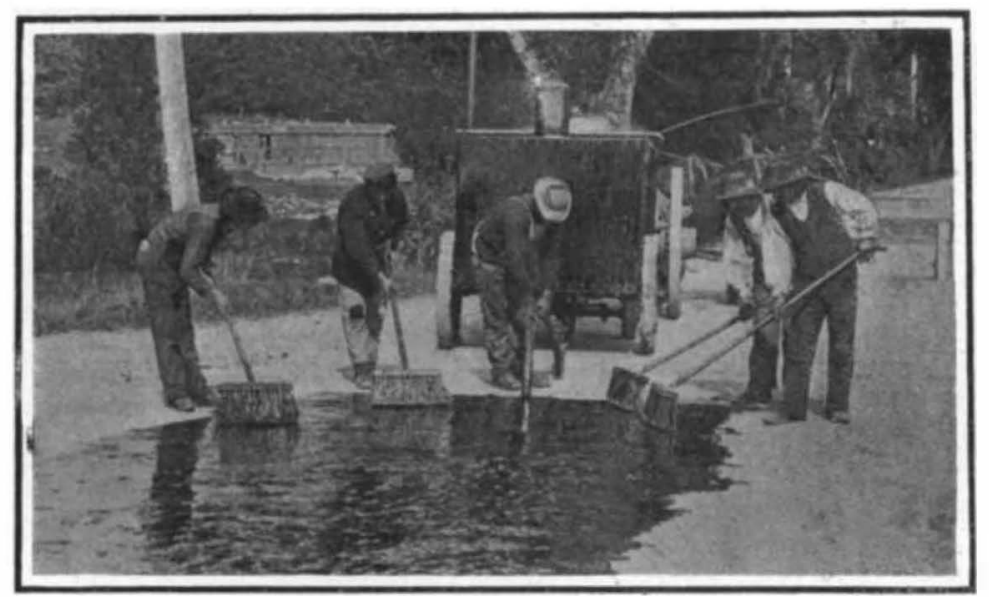

APPLYING SPECIAL TAR BINDER AT WESTWOOD, MASS.

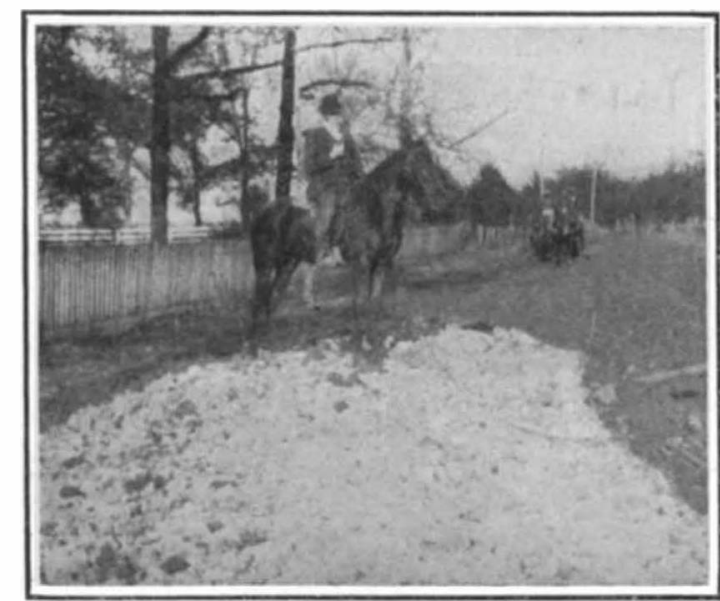

SOBGRADE COURSE BEFORE ROLLING

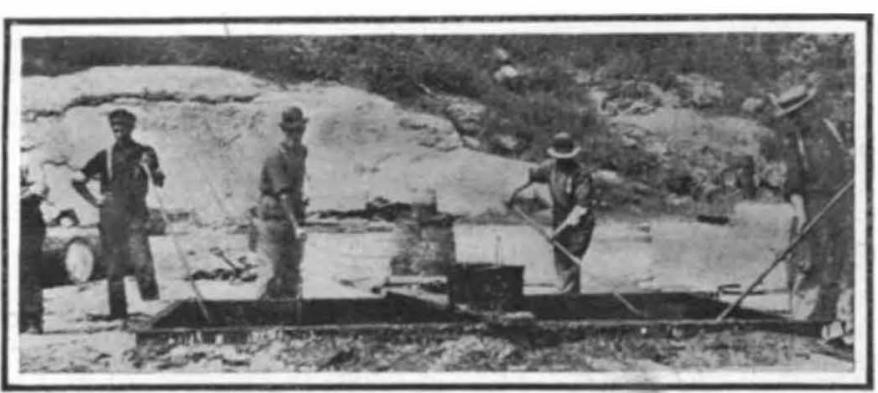

MIXING THE INGREDIENTS OF A "CANDY" ROAD (MOLASSES,

ETC.) THE SUGAR OF THE ROAD REFUSE TO COMBINE WITH ANY LIME THAT MAY BE APPLIED.

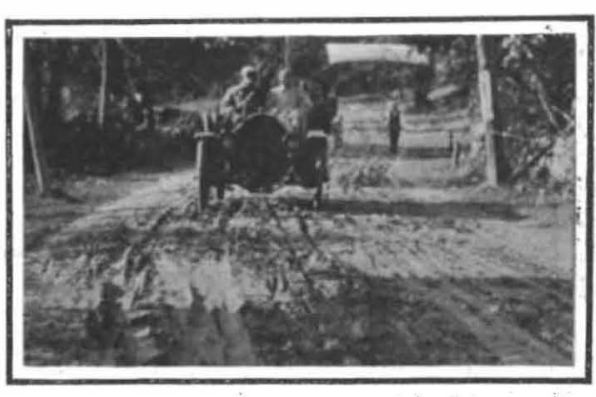

ROAD IN FAIRMONT PARK, PHILADELPHIA, AFTER BEING SOBJECTED TO SPEEDING AOTOMOBILES.

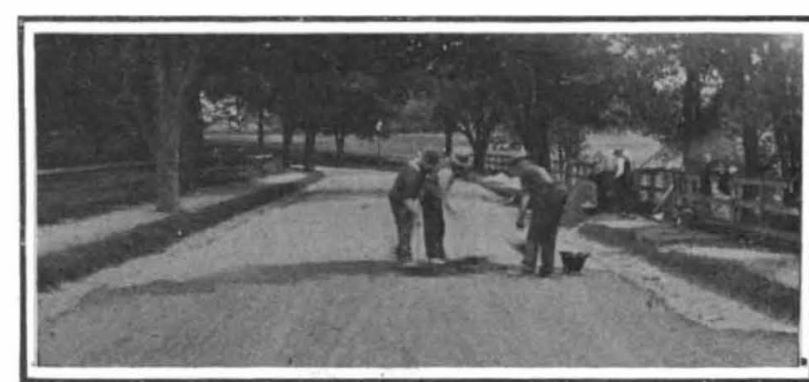

APPLYIMG. A FIXAL COAT OF TAR TO A ROAD BOILT ESPECIALLY FOR HIGH-SPEED AOTOMOBIIE TRAFTIC. 
THE MOTOR CAR AND THE ROAD. (Continued from page 47.) permanent binders include the petroleums containing an asphaltic base, the residues of such petroleums, the heavy tars, pitches, and numerous oil, tar, and asphalt preparations. In addition to these, a few special materials have been the subject of experiment, such, for example, as the waste product from the beet and cane sugar factories. In some insiances glue and bichromate of potash have been added to oil or tar emulsions to cause the residue upon the road surface to harden after the volatile products have evaporated. Waste sulphite liquors from wood pulp have been employed with some success in a concentrated form, and, in fact, the list might be indefinitely extended. The essential requisite in a dust preventive is its binding power, and it naturally follows that the experiments will cover a wide field.

Water, while usually the most abundant and cheapest material, is very often, be cause of the frequency with which it must be applied, the most expensive to use. It binding power is almost entirely due to tions commonly used lies in the hygroscopic character of the dissolved salt, which, having considerable affinity for water, keeps the road surface in a moist condition long after a surface treated with water alone would have become dry through evaporation. The light oils and tars, as well as the oil and tar emulsions, are dependent for their effect upon the retention by the road surface of a comparatively small amount of true binding base after the volatile products have evaporated. This base proves effective only as long as it retains its binding power When the binding power is destroyed, it is necessary to apply more material. If the base is an exceptionally good one, the accumulated products finally harden the road surface and prevent wear to some extent.

The heavy oils and tars differ from the lighter products in that they contain a much greater amount of asphaltum, which constitutes the binding base. The results are, therefore, of a mōre lasting charac ter, and hence the name permanent binders. The semi-solid and solid preparations usually contain a still greate amount of binder. With some few exceptions, all of the true binders are bitumens, and these bitumens may be either natural or artificial.

The usual method of applying these materials to the road surface is by sprink ling. The temporary binders can usually be applied cold, but the permanent bind ers, because of their much greater vis cosity, must be heated until sufficiently fluid. In England and France the use of coal tar is practised to a large extent and their methods of application have been highly developed. Machines are in gen eral use which are self-propelling and i which the tar is heated and then applie to the road surface as a spray under hig pressure. These so-called "tar sprayers" are not only very economical in the use of $\operatorname{tar}$, but insure a more even distribu tion and better penetration of the road surface than it is possible to obtain in almost any other way.

In the construction of dustless roads, the crucial question is that of cost. Automobiles have but little destructive effect on pavements, but these are in general too costly for country roads. The effort must be to develop a form of construction which will withstand fast automobile traffic and at the same time be within the financial resources of the community. This is largely being dona at present by the use of a bituminous binder instead of the rock dust. The two methods generally employed are known as the penetration and the mixing method. In the for mer, the hot liquid binder is sprinkled or sprayed over the stone and allowed to penetrate through the voids and coat the stones usually to a depth of two or three inches. Some of the devtces in use force the binder into the road surface by means of heavy air pressure. In the mixing

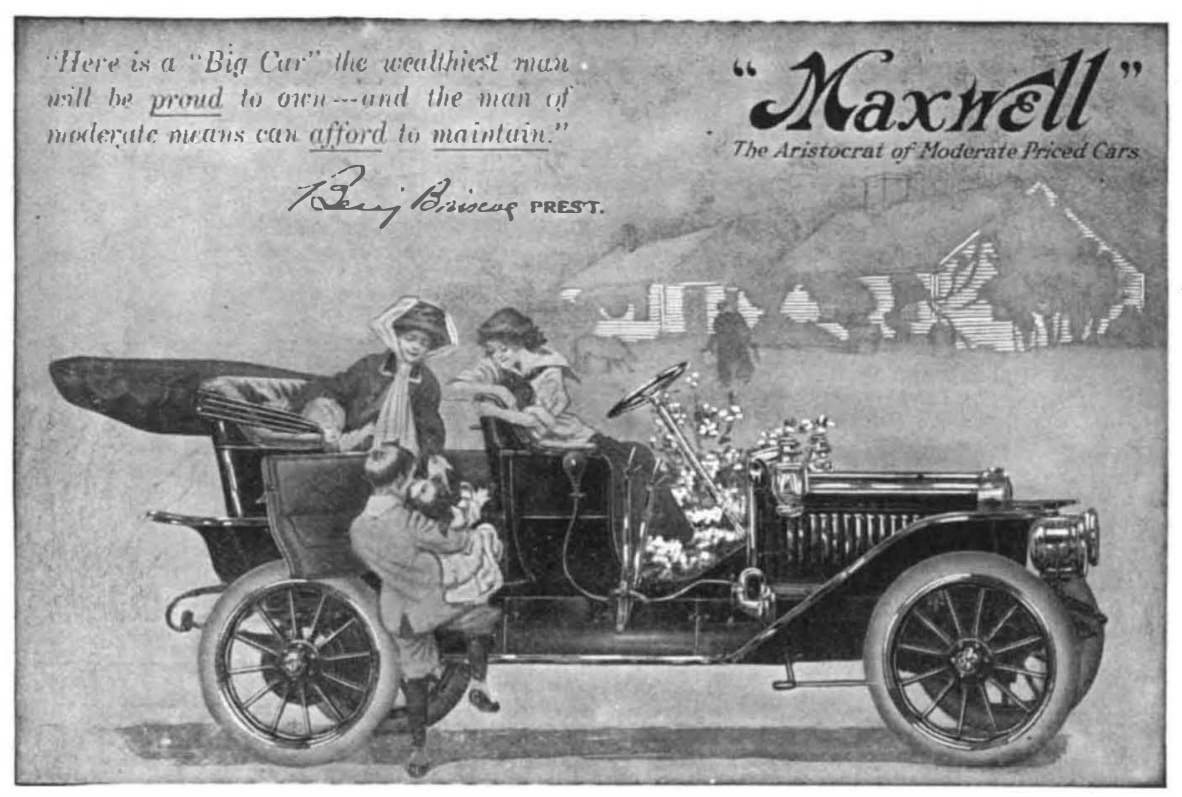

"This Car Can Be Run 5,000 Miles a Year at an Total Cost of $\$ 3.98$ a week" Average

Here is a Big Touring Car that will interest thousands of men who have always considered an automobile beyond their means- not because they couldn't afford to buy one, but because they have felt they couldn't afford the cost of maintaining one. It is true that the expensive "up-keep" of most automobiles has put them beyond the reach of men with moderate incomes. Not so with the Maxwell. Our cars have always been the most economical to run, as over 20,700 Maxwell owners have proved. Our constant aim has been to make automobiles that the mass of the people could afford to own. We have kept right on from year to year improving Maxwells in every smallest detail that would reduce their operating expense-increasing strength and durability, decreasing weight, and simplifying construction.

Now we are satisfied that in our new 4-Cylinder, $30 \mathrm{H}$. P. Touring Car we have the great "Economy Car." What does it actually cost to run? This is what the majority of men want to know, and this is just what you don't find out about other automobiles-before you buy them

\section{BASED ON FACTS}

When we tell you that this big, handsome Ma well Touring car can be run 5,000 miles a year at a average total cost of $\$ 3.98$ a week (or $\$ 207.02$ a year)
we are not theorizing. These figures include the total cost of gasoline, oil and grease required to run of two extra tires complete (which may not be
need ded) and the cost of repairs. Experience shows this to be a correct average, established by Maxwell owners. How can we better show the low cost of keeping a Maxwe11 than by giving in dollars and cents just what 5,000 miles of motoring cost
this owner? Read thisletter-one of hundreds we this owner? Read this

"During thepast season I have driven my car s,ooo miles by the odometer, averaging approximately 100
miles a week. My experience has shown that this car miles a week. My experience has shown that this car can be run 5 .
of 3.98 a week

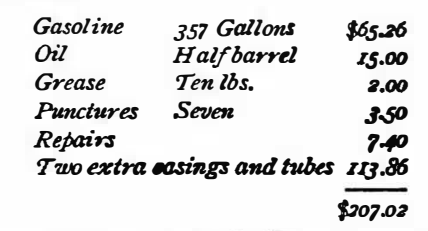

My running cost has actually been lower than the above figures, because at the beginning of the season 1 fact but one of these has been used, so that the car $h$ cost me per week, inclading everything, but \$3.o6.
E. L. CALKINS.

NOTE:-Fac-simile of this letter sent an reques

CHEAPER THAN TROLLEYS As these figures show, the average cost per
week is but 83.98 to run this big Maxwell 100 miles. week is but 83.98 to run this big Maxwell 100 miles. Thus making the total running cost per mile just that you can take a family of five for an outing in this car at less expense than you could take them twenty miles out of New pork and a trolley ride at least twenty cents each way, a total of $\$ 2.00$ Five people can make a round trip in this big Maxwell touring car at a total cost of $\mathbf{8 1 . 6 0}$. Surprising as this statement seems, it is true, and we have included it here to furnish you with a
striking example of the practical advantages of
our great "Economy Car."

\section{WE HELP YOU}

Proper care is of vital importance in keeping
down the cost of maintenance in any car. More automobiles are ruined from misuse than in any other way. We publish regularly, a semi-monthly magazine for Mazwellownersloshow them how to un their cars as cheaply as possible. For to run must run it with proper care. In giving the above ot to attempt to fool ourselves. We do not guarabove stated cost-though many Maxwell owners do even better. What we do want to show is that here is an automobile that thousands of people can afford to own, and to give average figures, showing of course.

These Books Free $\begin{gathered}\text { We want to send without cost to you, a copy of our magazine "The } \\ \text { co-Operator"-" How to judge an Automobile"-a practical treatise on }\end{gathered}$ motor cars. Our latest catalog describing and picturing every car we
manufacture, together with other interesting booklets of facts. One of these booklets giving the details that has never been equalled by any car at any price. These books will be sent by return mail without cost to you-just say-mail books.

MAXWELLS IN USE TODAY 20,784 .

MAXWELL-BRISCOE MOTOR CO. DEW STREET, TARRYTOWN, N. Y.

Pawtucket, R. I. Providence, R. I. Eingsland Point, N. Y. New Castle, Ind, method, the stones and binder are thoroughly mixed, either by hand or machine, so that each stone is covered with a thin film of the binder. This method in general insures the better and more even distribution of the binder throughout the road surface.

The material used for the binder varies very largely with different sections. In England and France the tars are used very largely. In the western portion of che United States, the heavy asphaltic oils of California are used almost exclusively, while in other sections we find that tars, residuum oils, liquid asphalts, and various proprietary compounds are being used.

One of the chief causes of the great number of failures which have been recorded in the use of bituminous road materials is the failure of the user, as well as manufacturer, to understand certain fundamental principles. To many, a tar is simply a tar and oil an oil, while in reality there is a vast difference sometimes even in the tars produced at th? same works. The oils also range from those of a paraffine base to those almost wholly asphaltic. Thus a concise knowledge of the character of the product, the process followed in its preparation, and the effect which varying conditions will have upon it is necessary in order to avoid costly mistakes.

THE MIDDLE WEST AND THE AUTOMOBILE INDUSTRY.

(Continued from page 48.)

that the freight has usually been added to the purchase price of the car, and has gone against the consumer, there are many cases in the past, and there will be many more in future, where the cars are sold directly at the catalogue price. For that reason, the location of factories in the middle West was ideal, for it is in truth the center of the automobile-buying public.

In some cases, cities have been made over and their population doubled and trebled by big motor-car factories, as in the case of Flint, Mich., and New Castle, Ind. Such cities have had a tremendous boom in real estate, and in business generally, owing to the influx of 2,000 to 5,000 families, and have assumed an entirely different position on the map because motorcar factories were established within their limits. Besides supplying employment to laborers in large numbers, much money has been made by the leaders in the various enterprises. This has been especially rue among the makers of wheels, tires, rames, and other parts. In a general way, it may be said that the parts makers have made more money than the automobile builders, as the latter have expended greater sums of money in experimenting.

The total capital of the automobile manufacturers in this country is about $\$ 225,000,000$. The actual value of the plants will run into some extraordinary figures, and these values are rapidly increasing. As for the output for 1910, it is likely to exceed $200,000 \mathrm{cars}$, although there may be a slight falling off from these figures, owing to the inability of parts makers to supply the demand. There are now about 150,000 automobiles in use in this country. In a general way, it may be said that the employees num ber some 120,000 is motor-car factories, with employees in parts factories reaching not less than 40,000 , a total of 160,000 . America may be safely considered the home of the low-priced car, a condition brought about by the tremendous buying power of the middle classes, who demand a car which can be cared for by the owner without the aid of an expensive chauffeur. These low-priced cars have been made possible by ideal factory methods and big production. This necessitated their being standardized, something that may be said to be original with the American maker, who feels that any one of ten thousand parts should be made to fit any one car turned out by his company.

By working on big productions and 